\title{
Tres Notas Sobre Pineda y Bascuñán
}

El Cautiverio feliz, libro famoso de las letras coloniales chilenas, narra las aventuras de un criollo, el maestre de campo general don Francisco Núñez de Pineda y Bascuñán, quien cayó prisionero de los araucanos en 1629 , y al convivir con ellos se transformó en su defensor. Estudios recientes sobre el Coutiverio mantienen la atención por el curioso texto; la variedad de perspectivas de esos trabajos muestra el carácter misceláneo del libro: se le considera historia anovelada, ${ }^{1}$ testimonio del peculiar mestizaje chileno, ${ }^{2}$ o bien una crítica del sistema colonial de su época, ${ }^{3}$ en lo social y político; por otra parte, se recuerda a Pineda como autor que anticipa las futuras corrientes indigenistas, ${ }^{4}$ y como fuente para conocer el "reverso de la conquista", la visión araucana de los españoles." Tantas muestras de interés, sin embargo, no han llevado modernamente a los estudiosos a dos tareas básicas: la revisión completa del texto original manuscrito, lo cual como suele ocurrir guarda sorpresas, y la investigación de archivo para aclarar la vida y personalidad del autor, en buena parte ignorada. Siendo el Cautiverio obra eminentemente autobiográfica, el conocimiento histórico de Pineda no puede descuidarse. Algunos hallazgos documentales nos invitan a adelantar noticias.

1 Mariano Picón-Salas, De la conquista a la independencia (México, 1944), pp. 103-4. Se interesa en el aspecto narrativo Enrique Anderson Imbert, Historia de la literatura bispanoamericana (México, 1970), I, 124-127. También se ocupa de la obra, a propósito de los versos que inserta, M. Menéndez y Pelayo, Antología de poetas bispanoamericanos (Madrid, 1928), IV, XXXIX-XLII.

2 Alberto M. Salas, Crónica florida del mestizaje de las Indias (Buenos Aires, 1960), pp. 139-171.

3 Sergio Correa Bello, "El cautiverio feliz" en la vida politica chilena del siglo XVII (Santiago, 1965).

4 Concha Meléndez, La novela indianista en Hispanoamérica (Puerto Rico, 1961), pp. 31-33.

5 Véanse las obras de Miguel León Portilla, para México, La visión de los vencidos (México, 1959); para todo el continente, El reverso de la conquista (México, 1964). El tema lo amplía Alejandro Lipschutz, El probloma racial en la conquista de América y el mestizaje (Santiago, 1967), 2a ed., 114-146; su estudio sobre el Cautiverio, aunque interesante, es breve e incompleto. 
UN MEMORIAL INÉDITO

Tras larga e infructuosa búsqueda, don Diego Barros Arana se dio por vencido y creyó prácticamente imposible hallar ningún memorial de Pineda. ${ }^{6}$ Por fortuna tropezamos con uno de ellos, si no con el original, 1639, al menos con una copia notarial de 1680 . Es la primera prueba fehaciente de cómo cayó y anduvo prisionero de los araucanos, pues la versión que ofrece su contemporáneo, el jesuita Diego de Rosales, y las de todos los cronistas posteriores se fundan en el propio Pineda. La veracidad de nuestro autor encuentra apoyo en el mismo documento: el gobernador y capitán general de Chile, don Francisco Laso de la Vega, presente cuando la liberación del jefe criollo, afirma que lo referido por éste en el memorial le "consta ser zierta y verdadera la relazión que haze"; ésta consiste en un escueto recuento de servicios destinados a retener una encomienda que peligraba al no hallarse aún confirmada por el rey. El suscinto pasaje sobre la batalla y los siete meses que estuvo en poder de los indios, ocupa parte importante dentro del breve escrito:

Siendo capitán en la desguaza ${ }^{8}$ que tubo el tercio de San Phelipe de

- Una importante colección de memoriales sobre las guerras de Aranco fue recopilada por Diego Barros Arana, quien la utilizo con gran provecho en su monumental Historia de Chile (Santiago, 1884-1902), y aunque buscó con empeño un memorial del autor del Cautiverio, cuya única edición completa prologó, hubo de concluir que la firma de nuestro autor "no se halla al pie de ninguna de esas solicitudes. La reseña de sus méritos y servicios, esto es su biografía de pretendiente, no fue escrita por él"; véase Francisco Núñez de Pineda y Bascuñán, Cautiverio feliz y razón de las guerras dilatadas de Chile (1673), en Colección de bistoriadores de Chile (Santiago, 1863), III, Introducción.

7 Archivo Nacional, Santiago de Chile, Real Audiencia, vol. MLXXXIV, pieza 2a. El legajo incluye cuatro documentos que en 1680 presentó don Fernando de Pineda, hijo primogénito de nuestro autor, para establecer su derecho sobre un indio fugitivo; aparecen alli el memorial, 23 de marzo, 1639; la respuesta del gobernador, dos días después, con la nómina de los 76 indios encomendados; la toma de posesión por el favorecido, 17 de junio, 1639; y cédula real aprobatoria dirigida a Pineda, 8 de octubre de 1641. Un pormenor interesante: en esa ratificación de la encomienda protocolizada el 17 de junio, firma como testigo el maestre de campo don Santiago de Tesillo, el importante cronista; las obras de éste, Guerra de Cbile, causas de su duración, advertencias para su fin, ejemplarizada en el gobierno de don Francisco Laso de la Vega (Madrid, 1647), y Restauración del estado de Arauco (Lima, 1665), fueron ampliamente usadas por Barros Arana en su historia y se reimprimieron en los vols. V y XI de la Colección de bistoriadores de Cbile (Santiago, 1864 y 1878). Ver también J. T. Medina, Historia de la literatura colonial de Chile (Santiago, 1868), II, 221-235.

8 Desguaza se lee claramente en el manuscrito que traslada en el mismo Santiago un original sólo cuarenta años anterior, pero esa voz no figura en los 
Austria con el enemigo, peleando en el escuadrón sin desamparar su puesto, por la gran fuerza de el enemigo y la poca de su partte le degollaron y cautibaron toda su jente, y al dicho capitán Don Francisco de Pineda le maltrataron de un malcanazo con que le de [r] rivaron en tierra, y desatentado de el golpe, le cautivaron y llevaron a sus tierras, adonde pasó muchos travajos por servir ha su Magestad, y peligros de vida; y por las dilijencias que hizo el señor presidente Don Luis Fernández de Córdova, su antezesor de Ussía, salió de el dicho cautiberio en tiempo que Ussía entrava ha governar este Reyno, como ha [sic] Ussía consta.

Los hechos ocurrieron en 1629, y al punto la aventura ganó fama cuasi legendaria, pues hacia 1634 inspiró una obra teatral en el Perú. Aunque el memorial sea de 1639 - cinco años posteriores a la comedia limeña- resulta aún de fecha bastante temprana; cronológicamente su interés aumenta si pensamos que la redacción del Cautiverio feliz se concluye muy tardíamente, en 1673. El memorial of rece además noticias sobre el autor durante el decenio que corre entre 1629 y 1639, mal conocido hasta hoy: por entonces, según ese documento, don Francisco peleó en las batallas de Los Robles y la Albarrada; fue corregidor y justicia mayor de Chillán, y llegó a comisario general de caballería.

Se ha considerado el Cautiverio feliz como semi-novela; ello se ha debido a los coloridos recuerdos autobiográficos, los cuales, de otro lado, no son sino parte de una compleja obra también preocupada por asuntos políticos, jurídicos y morales. La presente relación de 1639 , autorizada por un contemporáneo inmediato, el gobernador Laso, prueba que aun cuando los hechos provocasen una leyenda, existe base real. Esto invita a deslindar con mayor cuidado lo histórico y lo novelesco en esa importante obra colonial chilena.

diccionarios de americanismos de Georg Friederici, Marcos A. Morínigo y F. J. Santamaría, ni en los de chilenismos de Rodolfo Lenz y Manuel A. Román. Parece significar lo mismo que el indigenismo antillano guazábara, 'guerra entre españoles e indios"; para Morínigo, "es de las más antiguas voces que entró en el español americano y se difundió por todo el continente durante el siglo xvr". Según Corominas, al cruzarse con bullanga parece haber dado guasanga, 'algazara, baraúnda', y de ahí pudo extraerse guasa, en Cuba 'jolgorio, alegría ruidosa'. Desguaza, pues, resulta una variante desconocida de guazábara. 


\section{II \\ la "RECOPILACión" EN EL MaNuscrito original}

Desde que Barros Arana imprimió el Cautiverio feliz en 1863, prácticamente no se ha vuelto a estudiar el original. Revisándolo y comparándolo con cartas escritas por el autor, puede establecerse que es autógrafo, ${ }^{9}$ quizás integramente, o al menos en su mayor parte: hay varios tipos de letra, pero pueden proceder de la misma mano.

Al fin del voluminoso manuscrito se hallan tablas y apéndices: "Indice de algunas cosas particulares", "Resumen de los discursos y capítulos del libro", "Resúmenes de capítulos del Tratado esencial y. conveniente para los medios que pueden ser eficaces para el fin último de esta guerra de Chile", "Indice de las autoridades de sanctos autores y de otros autores graves y humanistas antiguos", "Indice de los lugares de la sagrada escritura que en este libro se contienen"; suman en total 95 folios. Hay asimismo una "recopilación" de 28 folios, sin numerar. Los dos primeros apéndices figuran al fin de la edición de Barros Arana; el tercero lo transcribió Sergio Correa Bello en 1967. El resto permanece aún inédito, pese a resultar útil para conocer las ideas de Pineda $y$ las lecturas que tuvo.

Hasta hoy subsiste la afirmación de Barros Arana de que la "Recopilación" es mero extracto del libro; ${ }^{10}$ opinión inexacta, según fácilmente podemos ver en varios ejemplos. En ese texto inédito aparecen asuntos explícitamente propios, y así se lee: "...la poca estimación o ninguna que tienen oi las armas, i los que las professan, en estas prouincias de las Yndias, es el principal blanco de esta mi epilogación i summa"; esas palabras de Pineda revelan conflictos de una sociedad en transición: ya pasado el siglo predominantemente bélico del XVI, ${ }^{11}$ los varios sectores

9 Esperamos publicar en breve trece cartas inéditas, de puño y letra de don Francisco a diversas personas: cinco están fechadas en 1650, una en 1667 y las otras van de 1670 a 1675 . La última firma, ya temblorosa, que conocemos de Pineda se halla en un protocolo fechado en Lima, 24 de mayo de 1680, días antes de morir (Archivo Nacional de Lima, sección notarial, protocolo de Pedro Arias de Ron, 1680-1682, f. 243v.).

10 Diego Barros Arana, Historia jeneral de Cbile, V, 418.

11 Varios autores muestran cómo Chile vivía en el siglo xvir una sociedad colonial ya estabilizada, rutinaria, con fronteras claras y bien resguardadas para contener a los indios peligrosos. En especial, ver Alvaro Jara, Guerre et société au Chili: essai de sociologie coloniale; la transformación de la guerre d'Araucanie et lesclavage légal 1612 (Paris, 1961); y Domingo Amunátegui Solar, La sociedad de Santiago en el siglo XVII (Santiago, 1937). 
de la población hispánica con inquietudes diferentes, muestran su descontento ante esas luchas inacabables y critican las actividades guerreras, que representaban antiguamente el único camino hacia la honra: ". . ha llegado a tal estado el vituperio, el escarnio i moffa que hazen de los soldados que descaradamente han dicho algunos liscenciados $\mathrm{i}$ Proffesores de las Letras que el seruir al Rei nuestro señor en sus exércitos es imfamia i descrédito de los que lo hazen: ¿de adonde nace este desprecio? ¿Y la altiués i mayoría de los Doctores i liscenciados?".

En otro lugar de la "Recopilación", Pineda copió íntegramente una carta que no menciona en el Cautiverio feliz. ${ }^{12}$ Ambos escritos tienen el mismo número de discursos y capítulos, pero contra lo que suponía Barros Arana la correspondencia ofrece variantes de interés. Vemos así en el Cautiverio:

"... babiéndome quedado en casa del cacique Quilalebo, me regocijaron todos los de aquel distrito; acupándonos en algunos entretenimientos, y a veces íbamos a ayudar a las mujeres a sembrar sus chacras, adonde iba a buscarnos el caique; y de la conversación que trabamos, y las cosal que se rodearon para tratar de las acciones de muestros conquistadores. Dejóme Tureupillán, mi antiguo huésped en aquella parcialidad, en casa de su amigo y deudo Quilalebo, a súplica y ruegos dél... Salíamos a la campaña a entretenernos unas veces a la pelota, otras a la chueca, ${ }_{2}^{13}$ y a ratos íbamos a ayudar a las mujeres a sembrar lo que habíamos arado, que de la mesma suerte se convidan a la siembra que los indios a la cava: asistimos con ellas una tarde, ayudándolas a beber mas que a trabajar, y

12 Carta del virrey Conde de Alba de Liste al maestre de campo general don Francisco de Pineda Bascuñán, Lima, 9 de octubre, 1656; la dio a conocer Sergio Correa Bello, op. cit., pp. 127-8, limitándose a transcribir el texto sin comentarlo ni referirse en nada a las relaciones de ese epílogo olvidado con el texto principal. En el mismo capítulo de la Recopilación, Pineda menciona con grandes alabanzas a los virreyes Marqués de Guadalcázar, Conde de Chinchón, Marqués de Mancera, Conde de Salvatierra y Conde de Alba; se extiende más en este último para aplaudir su ayuda a los chilenos cuando el alzamiento general de 1655, luego reproduce dicha carta. Nada de ello aparece en el Cautiverio y esos elogios per-' miten advertir el sentido de las censuras contra "gobernantes" que abundan en el Cautiverio. De otro lado, el que Pineda alabe cronológicamente a los virreyes y se detenga en Alba de Liste (1655-1661), resulta útil para explicar el proceso de redacción del libro, hasta hoy mal estudiado; al final del manuscrito se superponen dos fechas, 1663 y 1673: ¿Se terminó una primera redacción, más la Recopilación, en 1663? ¿Se revisó el manuscrito durante la permanencia de Pineda en el Perú, terminándose definitivamente en 1673, antes de regresar a Chile como gobernador de Valdivia? No ha de faltar información que permita despejar esas interrogantes.

13 Alonso de Ovalle describe los juegos indios, los cuales se ilustran con grabados (Histórica relación del reyno de Cbile [Roma, 1646], p. 93). 
nuestro viejo Quilalebo, hallándose solo, vino en nuestra demanda y nos halló dando fin a un cántaro de chicha y comiendo unos bollos de maíz y porotos mui bien sazonados. Convidamos al viejo luego que llegó, y él se asentó a mi lado, echándome los brazos y diciéndome: capitán, mui enojado me tenéis porque no habláis a mi hija" (Disc. IV, c. 1, p. 304).

La Recopilación dará otros detalles personales, harto pintorescos:

A petición y súplica de mi nuebo Amigo Quilalebo me quedé en su caza, si bien con alguna repugnancia interior, aunque era forsosso mostrarme agradecido, disimulando el sentimiento que me asistía y me afligía el alma por el peligro i Riesgo en que quedaba de faltar a la obligación de nuestra Perffexión christiana. Por los aprietos que mi Amigo Quilalebo bazia para que me casase con su bija, o coanitase con ella. Pero quando nos valemos de la oración y del Auxilio Diuino, fácilmente atropellamos las más continuas y fuertes tentaciones que por delante nos pone nuestro común y Potestario, como lo experimenté en esta ocación (IV, c. 1).

Aun cuando la Recopilación haya llegado incompleta —se conservan sólo los discursos IV y V- merece mayor interés que el poquísimo que se le ha concedido.

\section{III}

PINedA Y LAS IDEAS DEL OBISPO VILLARRoel

En la "Tabla de autoridades" aún inédita, cuarto índice de los que van al final del Cautiverio, sorprenden las muchas menciones del célebre obispo don fray Gaspar de Villarroel; siempre sobre la misma obra: Comentarii in Librum Judicum (Madrid, 1636), cuyo posible influjo en Pineda merece considerarse. ${ }^{14}$ Este impreso, más los tres volúmenes de Semana Santa: tratados de los comentarios, dificultades $i$ discursos literales i místicos sobre los evanjelios de la cuaresma (Lisboa, 1631; Madrid, 1632; Sevilla, 1634) dieron notoriedad a Villarroel en España e Indias; era todo lo publicado por él en la Península antes de venir a Chile.

\footnotetext{
14 Véanse Víctor Maturana, O.S.A., Historia de los agustinos en Chile (Santiago, 1904), I, 356-511; Gonzalo Zaldumbide, Cuatro clásicos americanos (Madrid, 1951), pp. 187-220; y Rubén Vargas Ugarte, S.J., Tres figuras señeras del episcopado americano (Lima, 1966), pp. 1-63.
} 
Criollo quiteño, se le nombró obispo de Santiago en 1637; permaneció en Chile hasta 1651, año en que fue trasladado al obispado de Arequipa, Perú. Existe la posibilidad de que ambos autores se conocieran en Chile, aun cuando no lo diga Pineda; éste comparte con el obispo una actitud proindígena, pero ambos criollos poseen diferentes perspectivas: educado en la Compañia, tan empeñada en adaptarse a la situación de los araucanos, Pineda parece encuadrar en la línea del padre Luis de Valdivia, a la cual pertenecen otros dos jesuitas, el criollo Alonso de Ovalle y el peninsular Diego de Rosales; ${ }^{15}$ Ovalle pasó la mayor parte de su vida en Chile, hasta 1641, cuando viajó a Europa para no volver más a su tierra; mutió cuando regresaba, hallándose ya en Lima, 1651. El español Rosales desarrolló infatigable labor entre los indígenas desde que llegó a Chile, 1629, hasta su muerte, 1677. Pineda tampoco menciona a estos jesuitas en el Cautiverio, pero con ambos y con Villarroel, grandes figuras de la prosa del Xvir, está ligado por ideas comunes. ${ }^{16}$

La posición frente al indio chileno del agustino Villarroel no ha sido estudiada hasta hoy. Su obra más importante, el Govierno eclesiástico pacifico, y unión de los dos cucbillos, pontificio y regio (Madrid, 1656-1657), aunque escrita en Chile, demoró en publicarse unos diez años debido, entre otros contratiempos, a un naufragio. En esos gruesos infolios se hallan abundantes noticias para comprender la sociedad de la época. ${ }^{17}$ El chileno Pineda y el obispo quiteño coinciden independientemente en la defensa del araucano. No hallamos huellas de los Dos cuchillos en el Cautiverio, pero esas menciones de la obra latina de Villarroel permiten imaginar un intercambia de ideas. ${ }^{18}$

La comprensión del obispo para con los indios rebeldes - cuya ferocidad provocó el que se les castigara con la esclavitud- lo lleva a plantear una explicación del sentido del canibalismo guerrero araucano. Sin llegar allí, Pineda muestra semejante actitud frente a ese pueblo, con el

I5 Alonso de Ovalle, S. J., op. cit.; Diego de Rosales, S. J., Historia general del reino de Cbile (Valparaíso, 1877-1878), 3 vols.

16 Un claro panorama general al respecto puede hallarse en Eugene $\mathrm{H}$. Korth, S.J., Spanish Policy in Colonial Cbile. The Struggle for Social Justice, 1535-1700 (California, 1968), pp. 162-187.

${ }_{17}$ Hay una reimpresión tardía (Madrid, 1738), 2 vols. Trabajando con diferentes ejemplares de la primera edición, el profesor José Durand y el suscrito, hemos advertido, independientemente, los temas de los mestizos llamados jenizaros y el canibalismo ritual araucano a que se refiere Villarroel: los estudiaremos en forma separada y nos encargaremos del segundo tema. Me indica el profesor Durand que las ideas jesuíticas de defensa del indio parecen venir en Chile del padre Diego de Torres Bollo, tanto respetado por Ovalle y Rosales. Torres Bollo alcanzó a conocer a jesuitas peruanos del XVI, en quienes parece hallarse un cierto influjo de Las Casas.

18 Gobierno eclesiástico (Madrid, 1656-1657), II, 307 y sigs. 
cual convivió. Además de su proverbial valor, Villarroel elogia en los chilenos "la agudeza en el pensar", inteligencia y facilidad para entender y aprender. En su comportamiento fiel y "gran fineza en la amistad", los juzga ejemplares. $\mathrm{Y}$ concluye:

"Verdaderamente que son acciones éstas que demuestran generosidad de ánimo, pecho noble, ilustre sangre y un natural discursivo, regido y encaminado de un entendimiento vivo y cultivado: con que no son tan bárbaros como lo hacen, tan crueles como los pintan, ni tan mal inclinados como juzgan los que no han experimentado sus tratos ni los particulares modos de vivir de algunos (que claro está que adondequiera se diferencia la plebe y el común de lo particular de la nobleza); que nuestra doctrina y enseñanza ha sido la que les ha dado mucho que pensar y en que entender, por haber sido las obras mui diferentes de lo que prometieron las palabras." (Disc. II, c. 9, p. 124).

De modo parecido pensaba, por su experiencia misionera jesuítica, el criollo Ovalle (y tambiên el peninsular Rosales). Escribe el padre Ovalle:

"Son naturalmente liberales, compasivos y amigos de hacer bien a todos, y los que les saben obligar honorándolos y tratándolos con la cortesía y respeto debido, son dueños de sus voluntades, y los muchachos llevados por bien son muy dóciles y fáciles de persuadir; pero si quieren llevarlos por mal, muerden la manta y lo hacen peor, $\mathrm{y}$ así tenemos hecha experiencia en nuestros estudios y escuelas, que se obligan más a estudiar procurándolos llevar por motivos de honra y suavidad, que por vía de rigor y aspereza." (Histórica relación, Libro V, c. 4).

Otra vez dirá el criollo jesuita que, aunque altivos, soberbios y arrogantes, los araucanos, al convertirse al cristianismo, "abrazan con gallardía y ánimo la penitencia". ${ }^{19}$

Muerto el padre Las Casas cien años atrảs, resulta instructivo ver, sólo en la región de Chile, a criollos como Villarroel, Ovalle y Pineda, gravemente preocupados por la suerte de los indios americanos.

\section{Ann Arbor, Michigan}

JosÉ ANADÓN

19 Histórica relación, lib. VIII, c. 14. 